\title{
Traditional and Innovative Educational Technologies at the University through the E- Learning Prism
}

\author{
Maria Krylova $^{1 *}$, Yulia Novikova ${ }^{1}$, Irina Totskaya ${ }^{2}$, and Irina Ostapenko ${ }^{1}$ \\ ${ }^{1}$ Azov-Black Sea Engineering Institute, Don State Agrarian University, 347740 Zernograd, Russia \\ ${ }^{2}$ Rostov State Transport University, 344038 Rostov-on-Don, Russia
}

\begin{abstract}
The article is dedicated to comprehension the process of technological education in relation to E-learning. The relevance of the study is determined by the situation connected with the COVID-19 coronavirus pandemic, which required various educational organizations complete transition to distance learning for an indefinite period. It is noted that various educational technologies have been gaining new implementations in the conditions of distance education. The trend towards the gradual rejection of traditional (explanatory and illustrative) teaching methods and the transition to innovative technologies that were being operated within the educational system over the past decades has undergone changes due to the widespread transition to distance learning. Traditional technology, which structure includes elements of interactivity and innovation, has proven its effectiveness in the circumstances of Elearning. The least effective ones, based on the authors' university teaching experience were training and game technologies. The technology of developing training can be effective if a teacher meets a number of conditions, depends on methods, means, and others learning technologies. Project technology, heuristic learning, problem - based learning, casestudy technology, and differentiated learning proved to be the most effective ones. It is noted that the effectiveness of technologies application in the process of distance learning largely depends on a's teacher professionalism and creative approach. The conclusion is made about the dynamism of the educational technologies system, its dependence on the conditions of training and the rapid development of educational technologies in response to conditions changes.
\end{abstract}

\section{Introduction}

Technological effectiveness is an important quality of the modern educational process. Technologies have firmly entered all aspects of our life, not bypassing education, where the requirement of technological effectiveness is consistent with the general ideas about the modernization of the educational process, the introduction of innovations into it. The technology of training (educational technology, pedagogical technology) is defined in

\footnotetext{
* Corresponding author: krylovamn@inbox.ru
} 
modern sources as "a set of the most rational ways of scientific organization of work that ensure the achievement of the set goal of training in the shortest time with the least cost of effort and resources" [1, p. 314]. As can be seen from the definition, the goals of technological effectiveness introducing into the educational process are to rationalize learning, that is, to choose the optimal system of its organization, and to reduce energy consumption - to minimize the time, effort and resources that will be applied in the learning process to achieve its results. Another goal that should be mentioned is the desire to meet the educational needs of students who are dependent on the trends of social development. As O. M. Smirnova and M. B. Balycheva note, "teaching is always guided by the values of the generation to which it is addressed. The modern generation believes, first of all, in technological knowledge" [2, p. 142].

\section{Problem Statement}

Technological effectiveness of education has become the subject of research of many modern specialists - scientists, methodologists, practicing teachers. O. M. Smirnova and M. B. Balycheva associate technological effectiveness with postmodernism, the actualization of virtual space, the needs of students in technological knowledge [2]. E. A. Kostina and Zh. S. Soboleva distinguish such characteristics of pedagogical technology as "scientific planning and forecasting, algorithmization, monitoring and controllability of the educational process" [3, p. 49]. E. Barbara, B. G. Kirschner emphasize the need to take into account the time factor when choosing educational technologies [4]. Y. J. Kang, A. D. Ritzhaupt state that the application of educational technologies is primarily focused on such areas as "instructional design, project management, technical skills, and soft skills" [5, p. 231].

At the moment, in connection with the COVID-19 coronavirus pandemic, the importance of distance education has increased in the educational systems of countries all over the world $[6,7,8]$. At the beginning of 2020 , there was a need for a quick and effective transition to those forms of learning that can be implemented at a distance. Teachers had to take a fresh look at educational technologies, rethink their importance regarding the possibility of using them remotely, in the E-learning format.

\section{Purpose of the Study}

The objective of this research paper is to consider traditional and innovative educational technologies that are actively used in modern educational systems, from the point of view of the possibilities and effectiveness of their use in the context of E-learning. In accordance with the objective, the following tasks were solved: to describe the system of educational technologies that are relevant at this stage of education development; to compare the overall effectiveness of the main educational technologies and their effectiveness in the conditions of E-learning; to determine the prospects for the development of educational technologies that correspond to the concept of distance education.

\section{Research Methods}

The study was carried out using methods of analysis, synthesis, observation, as well as systematic and integrated approaches. 


\section{Results}

The history of the development of education in the world followed the path of gradual and continuous introduction of new technologies. The most traditional, having a long application history, is the explanatory-illustrative technology. Applying it, the teacher explains the theoretical material using lecture and story methods, uses illustrations (posters, slides, notes on the blackboard), and then the students reproduce this material, trying to recreate the teacher's explanation as accurately as possible. At the moment, explanatory and illustrative technology is still actively used, but its effectiveness is questioned, its weaknesses are noted, such as the lack of feedback, copying the teacher's knowledge without deep understanding, poor consideration of the psychological characteristics of students, etc. [9, p. 219]. Nevertheless, there are studies, the authors of which, while recognizing the overall effectiveness of innovative technologies, speak of the high efficiency of the traditionally built educational process [10].

In the research literature the most effective ones are called innovative technologies, the list of which is currently very extensive and includes dozens of names. Let's list the main innovative technologies that are highlighted in contrast to the traditional (explanatory and illustrative): active learning; training technologies; heuristic learning; distance learning; play training; interactive approaches; computer learning technologies; method of projects; cooperation pedagogy; problem learning; developmental training; advanced learning; multilevel training; contextual learning; pair learning technology, etc. [11, p. 64]. As one can see, two of them (distance learning and computer learning technologies) are directly related to E-learning, that is, the concept of innovative technologies initially includes the possibility of E-learning, due to its high technological effectiveness.

The development of the system of educational technologies over the past decades has followed the path of gradual abandonment of explanatory and illustrative technology (at least, weakening of its importance) and strengthening the need to use innovative teaching technologies as actively as possible. So, W. F. Crittenden, I. K. Biel and W. A. Lovely note: "We contend that vested stakeholders - institutions of higher education, professional associations, publishing companies, and technology companies - need to support and strengthen faculty efforts in embracing technology to continuously enhance learning" [12, p. 5]. However, the complete transition in most educational organizations to distance learning with respect to the pandemic in 2020 forced educators to take a fresh look at educational technologies.

The experience of transition to distance learning made teachers take a closer look at such a familiar explanatory and illustrative teaching technology and see many positive aspects in it. Its indisputable advantages include: firstly, time saving (the teacher has the opportunity to give out a significant amount of information, give assignments, check the primary material perception for a limited time in the conditions of distance learning); secondly, respect for the efforts of the teacher and students (the saved energy can be used for distance learning using other technologies); third, making it easier for students to understand complex tasks (explanatory and illustrative technology provides detailed explanations, accuracy of information, wording unambiguity); fourthly, rather effective management of the educational process by the teacher (the teacher knows exactly what information is available to students, at what stage of training - topic, chapter - they are, what components of the material can be brought under control, etc.)

In the context of distance learning, the traditional (explanatory and illustrative) educational technology has again acquired the level of importance that it practically lost under the pressure of innovative technologies. However, teachers who actively use it for organizing distance learning need to remember about the shortcomings of this technology: it limits the independence of students, does not serve the development of their creativity, 
and does not stimulate the active participation of students in the educational process. Getting knowledge in a ready-made form slows down students' development of critical thinking, the desire to understand the problem, to construct personal build ways to solve it, to find original ways to achieve educational goals. Memory development becomes more important than thinking development; the students' individual characteristics turn out to be unimportant.

To overcome these shortcomings of traditional educational technology in the course of distance learning, it is necessary to introduce elements of other technologies into it, to provide permanently varying tasks aimed at developing the independence, activity, and creativity of students. For example, when issuing theoretical material, students can be invited to study one of the questions on their own, and not just by organizing a search for the necessary material, but by answering a problematic question or analyzing a specific situation (case-study method). In order to control the material perception, one can ask not ordinary, but heuristic questions, which are not directly answered in the synopsis or textbook. To answer heuristic questions, it is necessary to compare some facts, attract one's own experience and existing knowledge, carry out mental operations of comparison, analysis and synthesis, draw conclusions, establish interdisciplinary connections, etc.

We should not forget that any lesson, even an ordinary lecture, can be built interactively - "when each student is involved in the learning process; teaching is carried out in the form of interaction, dialogue - both between the teacher and the students, and between the students themselves" [13, p. 40]. To add interactivity to a lecture conducted on the basis of traditional technology, a teacher can introduce elements of conversation into it, include a pre-planned mistake in the text of the lecture, instead of presenting ready-made examples to students, a teacher should also encourage students by giving them illustrations from his own life, his experience, by introducing elements of advanced learning, etc.

One shouldn't also forget that one of the elements of traditional technology is the use of illustrations. The visual teaching method constantly confirms its effectiveness, since "usual technologies are increasingly accessible and affordable, and visual methods are at the forefront of methodological innovation" [14, p. 60]. Modern technical means help to make illustrative material bright, capacious, information intensive, and diverse. The teacher can on his own create presentations using Microsoft PowerPoint, or use ready-made presentations, video and audio materials located on any available Internet resources, the educator can also suggest students could independently create illustrative materials for the theoretical understanding of any topic (question).

For teachers, there is no doubt that E-learning is not very effective in organizing practical training [15]. Therefore, it is in this educational area that a particularly thoughtful choice of educational technologies is required. For practical and laboratory classes, as well as industrial practice, the teacher usually uses such educational technologies as training, heuristic learning, game technology, project method, problem learning, case-study, developing learning, differentiated learning, etc. In the context of distance education there have some difficulties appeared in the implementation of a number of these technologies, while others have turned out to be more convenient and effective.

Training technologies have shown themselves to be quite difficult to be implemented, since they require the use of a variety of equipment being available in the laboratories of the university, but it cannot be used by students for E-learning. Game technology also shows low efficiency, since its use requires the personal presence of the participants of the learning process and their direct interactive contact in the student-student and studentteacher paradigms. The technology of developing learning demonstrates its dualism: on the one hand, distance learning participants develop independence, dedication, responsibility, composure, scientific outlook, on the other hand, the development of creativity, general culture, educational activity, practical skills, and teamwork skills can be inhibited. 
Apparently, the use of the technology of developing learning depends to the greatest extent on how the teacher organizes classes, what methods and means of teaching he chooses, what basic educational technologies he relies on.

Educational technologies such as the project method, heuristic learning, problem-based learning, the use of case-studies, and differentiated learning prove their effectiveness and productivity in the course of distance learning.

The project method initially, even without the transition to E-learning, "consists in the implementation of an independent creative project under the guidance of a teacher" [13, $\mathrm{p}$. 45]. It means that the conditions of preparation for distance learning change are characteristic of little chnges. A teacher can also manage a project remotely, and he will only have to think over the organization of project protection. Heuristic and problem-based learning entirely depend on the teacher's ability to correctly select the learning problems that need to be resolved. Attempts to solve them may well be carried out in a distance format. The use of case-study technology is similar to the implementation of project technologies and problem-based learning: a skillfully selected situation is independently resolved by students in a distance format, and then its solution is handed in to the teacher for verification.

The technology of differentiated education benefits the most from the distance education format. Each student works in conditions convenient for him, comfortable in physical and psychological terms, in some cases - at a convenient time. He can choose from the multilevel assignments proposed by the teacher those ones that correspond to his basic training, level of knowledge and inclinations. The student completes the tasks individually and receives the teacher's response to them, intended specifically for him and evaluating exclusively his work. However, this technology requires a lot of stress from the teacher, a significant expenditure of energy and time for the preparation of differentiated assignments, individual interaction with each student, verification and assessment of each work.

Despite globalization, penetrating into all spheres of life of modern society, in the implementation of E-learning, there are processes specific to certain countries and regions. They may be linked to positive government E-learning policies. In particular, since 1999 the United States have been developing programs to support E-learning, with the goal of "conferring economic fluency and mobility to individuals within the society" [16, p. 365], which contributes to faster and more effective implementation of educational innovations. In other countries, for example, in Kenya, the introduction of E-learning is not so fast, which is hindered by "heavy workloads, <..> insufficient Internet connectivity, limited information and communication technology (ICT) skills, lack of incentives, shortage of computers / laptops, inadequate computer laboratories, and insufficient time for online interaction" [17, p. 140].

The introduction of E-learning in Russia is also associated with the need to solve a number of problems, including: the acquisition of the necessary equipment by universities, doubts of teachers and students' parents about the effectiveness of E-learning, the lack of readiness of students for self-study, as well as "low level of knowledge of information technologies university teachers" [18, p. 168]. The solution of these problems, as well as the choice of effective educational technologies, should become the primary task of universities and teachers at this stage of development of distance learning.

\section{Conclusion}

So, in the context of the forced transition to distance learning in connection with the COVID-19 coronavirus pandemic, there are transformational processes in the use of educational technologies by teachers. Their implementation in the course of E-learning 
forces teachers to reconsider their attitude towards them. The traditional (explanatory and illustrative) technology, which is convenient as a quick and low-cost tool for transferring educational information to students, is returning its lost significance. In modern conditions, teachers should strive to introduce elements of interactivity and innovative technologies into traditional lectures. A number of educational technologies have shown their low efficiency in transferring education to the Internet format: educational training, game technology, technology of developing education. A number of technologies turned out to be quite effective: the project method, heuristic learning, problem learning, case-study, differentiated learning.

The system of educational technologies in the context of distance learning during the coronavirus period has proven its dynamism, the ability to change rapidly depending on the forms that the educational process is taking on. The teacher always has the opportunity to choose the most effective technology based on the real situation in which he teaches. At the same time, the success of the choice completely depends on the professional level of the teacher, the degree of his technological preparation, and the creative approach to work.

Prospects for the study consist in clarifying the positive and negative aspects of using each of the educational technologies available in the arsenal of modern higher education teachers. It is also necessary to think about how one can improve the efficiency of using traditional and innovative educational technologies in order to make distance learning as effective as possible.

\section{References}

1. E. G. Azimov, A. N. Shchukin, New Dictionary of Methodological Terms and Concepts (Theory and Practice of Language Teaching) (Moscow, IKAR, 2009).

2. O. M. Smirnova, M. B. Balycheva, Postmodernism and technological effectiveness of education - the pros and cons, Science, education, youth in the modern world: Materials of the international scientific and methodological conference, Moscow, Russian State University of Oil and Gas, 141-146 (2016).

3. E. A. Kostina, Zh. S. Soboleva Theoretical comprehension of the essence and structure of the concepts "pedagogical technology", "technologization of the educational process", "adaptability", "criteria of adaptability" in the framework of university foreign language education, Humanitarian research. Pedagogy and Psychology, 3, 49$56(2020)$.

4. E. Barbera, B. G. Kirschner, Paradox of time in research on educational technology, Time \& Society, 24-1, 96-108 (2014).

5. Y. J. Kang, A. D. Ritzhaupt, A Job Announcement Analysis of Educational Technology Professional Positions: Knowledge, Skills, and Abilities, Journal of Educational Technology Systems, 43-3, 231-256 (2015).

6. M. V. Startsev, Distance education: where are the advantages? Psychological and pedagogical journal Gaudeamus, 19-2, 99-106 (2020).

7. P. Faisal, Z. Kisman, Information and communication technology utilization effectiveness in distance education systems, International Journal of Engineering Business Management, 12 (2020).

8. D. Yi, Accessibility analysis of distance education resources based on multiple constraint model, The International Journal of Electrical Engineering \& Education, 1 (2021).

9. K. S. Grigorieva, Comparative analysis of the innovative technology of differentiated education and the original traditional teaching technology, Pedagogical science and 
education in dialogue with time: Materials of the $V$ International scientific and practical conference (Astrakhan, ASU, 2020).

10. D. A. Veneri, K. Zdanis, Are technology-informed methods better than traditional approaches in educating patients? A meta-analysis, Health Education Journal, 77-3, 261-276 (2018).

11. I. A. Ostapenko, M. N. Krylova, Pedagogy of higher education: a textbook (Zernograd, AchII, 2017).

12. W. F. Crittenden, I. K. Biel, W. A. Lovely, Embracing Digitalization: Student Learning and New Technologies, Journal of Marketing Education, 41-1, 5-14 (2018).

13. M.N. Krylova, Interactive methods in the teaching of the humanities in a technical university, Prospects for Science and Education, 4, 39-46 (2016).

14. C. Owen, S. Riley, Teaching Visual Methods Using Performative Storytelling, Reflective Practice and Learning through Doing, Psychology Learning \& Teaching, 11-1, 60-65 (2012).

15. D. Diethei, F. Ertle, T. Grundgeiger, Ch. Mengelkamp, V. Held, E-Learning vs. ELearning with Hands-on: An Experimental Study to Improve Clinical Skills, Proceedings of the Human Factors and Ergonomics Society Annual Meeting, 61-1, 660 (2017).

16. E. A. Roumell, F. D. Salajan, The Evolution of U.S. e-Learning Policy: A Content Analysis of the National Education Technology Plans, Educational Policy, 30-2, 365371 (2014).

17. D. N. Mutisya, G. L. Makokha, Challenges affecting adoption of e-learning in public universities in Kenya, E-Learning and Digital Media, 13-3, 140-157 (2016).

18. E. A. Zhadko, E-learning technologies: problems of implementation in Russia, Economy, society, people: theory, methodology, reality: Collection of scientific publications (Yekaterinburg, USUE, 2015). 